\title{
Verdade pragmática
}

JATR MINORO ABE

$\mathrm{N}$

este artigo, fazemos um apanhado geral de alguns desenvolvimentos técnicos que têm sido feitos nos últimos anos sobre a verdade pragmática, que também chamamos de quase-perdade. Tais desenvolvimentos se devem, especialmente, a N. C. A. da Costa, R. Chuaqui, I. Mikenberg e S. French.

Há, pelo menos, quatro teorias da verdade que se evidenciam de relevância para o filósofo que se ocupa da Teoria da Ciência: 1ª) a Teoria da Correspondência, particularmente na forma que the conferiu $\mathbf{A}$. Tarski; 2a) a Teoria da Coerência; $3^{\text {a }}$ ) a Teoria Pragmática; $4^{a}$ ) a Teoria da Eliminação da Verdade (ou definibilidade da verdade). Sobre tais teorias o leitor pode consultar S. Haack (1980a e b), A. Tarski (1956 e 1944) e A. Grayling (1986).

Segundo a Teoria da Verdade como Correspondência, este conceito relaciona proposições, juízos ou sentenças a situaçōes reais; e uma proposição, um juízo ou uma sentença é verdadeiro se, e somente se, reflete a realidade. Em outras palavras, uma proposição é verdadeira se ela corresponde à realidade, se o que ela afirma de fato é.

Aristóteles, no Lipro $\Gamma$ da Metafísica, define a verdade da seguinte maneira: "Dizer daquilo que é, que é, e daquilo que não é, que não é, é verdadeiro; dizer daquilo que não $\epsilon$, que é, e daquilo que é, que não é, é falso' . Na Idade Média, os Escolásticos afirmavam que a verdade é a adequação entre pensamento e realidade.

As definiçóes anteriores são válidas e não podem servir de base para um tratamento lógico-matemático do conceito de verdade como correspondência. $O$ grande mérito de Tarski foi o de ter desenvolvido uma formulação matematicamente tratável da Teoria da Correspondência. Com isso, ele revolucionou a Lógica e lançou as bases da Teoria Clássica de Modelos, uma das partes mais importantes da Lógica atual, náo apenas relevante em si mesma, pelos seu notáveis resultados teóricos, como, também, pelas suas aplicações na Matemática, nas Ciências Empíricas e na Tecnologia.

A idéia central de Tarski foi a de considerar o conceito de verdade como consistindo numa relação entre sentenças de uma linguagem e a 
estrutura na qual esta linguagem está interpretada. Não há sentido falar de verdade ou de falsidade de uma sentença a náo ser que se saiba exatamente a que linguagem essa sentença pertence e de que modo a linguagem está interpretada.

A definiçăo de Tarski pressupóe que a linguagem de base possui uma estrutura bem definida, pois ela deve ser tratada do ponto de vista matemático. Por conseguinte, a definiçáo de Tarski se aplica principalmente às linguagens artificiais, simbólicas, da Lógica e da Matemática.

Não podemos apresentar, aqui, mesmo de modo informal, a Teoria de Tarski, dado que é demasiadamente técnica. No entanto, como ela é a base da Lógica tradicional, pode ser encontrada em bons livros de Lógica, como os de Shoenfield (1967) e de Mendelson (1979). Conforme a linguagem estudada, a definiçáo correspondente de verdade possui características peculiares.

No entanto, lembramos que o conceito de verdade, tal como Tarski o entende, deve satisfazer o que se chama esquema $T$, que, em um caso particular, é o seguinte:

T: "A neve é branca" é verdadeira se, e somente se, a neve é branca.

Em outras palavras, o esquema $T$, que a definiçáo de verdade de Tarski satisfaz, garante que a relaçáo é uma conexáo entre linguagem e realidade (na Teoria Abstrata de Modelos é uma relação entre linguagens artificiais e certas estruturas matemáticas que se chamam modelos).

A Teoria da Coerência náo considera a verdade como uma relaçáo entre linguagem ou pensamento e realidade. Ao contrário, concebe a verdade como sendo uma propriedade eminentemente lingüística, de caráter sintático; vários autores, de uma maneira ou outra, defendem a Teoria da Coerência, tais como G. Hegel, B. Bosanquet, F. Bradley e H. Joachim bem como alguns dos membros do Círculo de Viena, tais como O. Neurath e H. Hahn.

Segundo os adeptos da Teoria da Coerência, não se pode comparar uma sentença à realidade, para sabermos se a sentença é verdadeira ou falsa. Com efeito, a realidade nos afeta e através de nossa experiência podemos testar uma sentença; porém, como nossa experiência, também, se reduz a sentenças de determinado tipo, segue-se que, afinal, só se pode comparar sentenças com certas sentenças. $O$ cientista, enquanto tal, recebe um conjunto de sentenças que são aceitas como verdadeiras, que devem ser coerentes (não encerram contradições) e aspirar à maximalidade: isto é, o pesquisador sempre procura conjuntos coerentes 
maximais de sentenças. Sempre que uma parte de nosso sistema de crenças nấo funciona bem, devemos procurar modificá-lo, comparando-se sentenças entre si, de modo a se obter um novo sistema que seja coerente e, se possível, maximal.

Assim, Neurath diz que somos como um marinheiro que, no meio do oceano, tem que reconstruir o próprio barco.

A Teoria da Coerência é extremamente interessante e hoje a Lógica e a Matemática possuem meios para tratá-la de uma forma conveniente. Porém, como nosso objetivo é o estudo da verdade pragmática, não ampliamos mais nossa exposiçáo da verdade como coerência.

A Teoria da Eliminação da Verdade é a teoria cunhada por F. P. Ramsey, segundo a qual o conceito de verdade náo apresenta aspectos teóricos de grande relevância, pois pode ser eliminado. Por exemplo, afirmar que "A neve é branca" é verdadeira, equivale, simplesmente a afirmar: A neve é branca.

A teoria de Ramsey foi muito desenvolvida nos últimos tempos, existindo filósofos e lingüistas que a têm aplicado nas mais variadas circunstâncias.

Finalmente, a Teoria Pragmática da Verdade é a que tratamos com algum pormenor neste trabalho, por se ter convertido numa das mais importantes concepçóes de verdade, com significativas aplicaçóes à Lógica, à Matemática e à Filosofia da Ciência.

\section{As concepçóes de Peirce, James e Dewey}

A concepção pragmática da verdade se deve basicamente a C. S. Peirce, um dos grandes lógicos e filósofos do século passado e do começo deste, o criador do pragmatismo.

Peirce escreveu: "considere que efeitos práticos concebemos que o objeto de nossa concepçáo tem. Então, nossa concepçáo desses efeitos constitui o conteúdo total de nossa concepçáo desse objeton (C. S. Peirce 1965, p. 31).

A afirmaçáo de Peirce pode ser claramente interpretada como significando que a verdade pragmática de uma proposição depende de seus efeitos práticos, supondo-se, naturalmente, que esses efeitos sejam aceitos como verdadeiros, ou falsos, no sentido comum da palavra verdade.

Como se observa em Mikenberg, da Costa e Chuaqui (1986), esses efeitos podem ser formulados como certas proposiçóes básicas e, por- 
tanto, uma asserção (hipótese ou teoria) pode ser tida como pragmaticamente verdadeira se suas consequiências básicas são verdadeiras, no sentido da Teoria da Correspondência. Para eles, esta interpretação do dictum de Peirce constitui a essência da Teoria da Verdade de Peirce.

Assim, a verdade pragmática é fundada em suas conseqüências básicas ou efeitos práticos, e năo se mostra completamente independente no sentido de correspondência com a realidade. Como afirmam da Costa e Chuaqui: "Ao contrário, um enunciado - em geral, um enunciado teórico - é pragmaticamente verdadeiro somente quando os enunciados básicos que ele implica são verdadeiros no sentido da Teoria da Correspondência da Verdade. Mas, ainda, uma asserçáo básica é verdadeira, do ponto de vista pragmático, se, e somente se, ela é verdadeira de acordo com a Teoria da Correspondência. Assim, a verdade pragmática não é inteiramente arbitrária" ( $\mathrm{Da}$ Costa e Chuaqui, no prelo).

Acrescentam da Costa e Chuaqui: "Em geral, pode-se manter que em Ciência sempre obtemos verdade pragmática, embora a verdade pragmática assim obtida se aproxime da verdade" (no sentido da Teoria da Correspondência). Tal idéia pode ser tornada rigorosa por meio da nossa definição de verdade pragmática... E esta parece ser, também, a posição de Peirce. Por exemplo, ele afirma: "Diferentes pessoas podem começar com os mais antagônicos pontos de vista, mas o progresso da investigaçáo acaba por levá-los, forçosamente, para fora de si mesmos, à única e mesma conclusão. Essa atividade do pensamento por meio da qual somos levados, não aonde desejamos, mas a uma finalidade pré-fixada, é semelhante à questáo do destino. Nenhuma modificação do ponto de vista inicial, nenhuma mudança natural de postura, pode fazer com que um homem escape da crença predestinada. Esta grande esperança é englobada na concepçáo da verdade e da realidade" (Peirce 1965).

Os autores em questáo desenvolvem as idéias anteriores da mesma forma que Tarski formalizou a Teoria Clássica da Correspondência. Antes, porém, de mostrarmos como se efetua isto, diremos alguma coisa sobre as concepçóes de James e de Dewey (consultar S. Haack 1974 e 1980).

James reformula a definiçáo de Peirce, levando em conta, especialmente, questóes não-científicas. Em particular, procura estabelecer uma Teoria da Verdade Pragmática que justifique as crenças religiosas. Falando-se sem rigor, a crença em Deus, por exemplo, seria pragmaticamente verdadeira se suas conseqüências, na vida de todos os dias, fossem interessantes, agradáveis e convenientes para a pessoa que crê. 
Muitas vezes se sustenta que a teoria de James é muito menos rigorosa que a de Peirce e que carece de valor científico. Nossa opinião é diferente: embora a teoria de W. James divirja da de Peirce, e muitas de suas teses não tenham sido aceitas por Peirce, seria deveras interessante formalizarmos os aspectos mais salientes da posiçáo de James no tocante à verdade.

Dewey sustentou uma Teoria da Verdade baseada na noção de assertabilidade garantida (warranted assertibility). Do ponto de vista atual, utilizando-se não apenas recursos lógicos e matemáticos usuais, como, também, métodos da Teoria dos Sistemas e do Cálculo de Probabilidade, talvez a teoria de Dewey pudesse ser matematizada.

\section{Formalização da Teoria Pragmática da Verdade}

Mikenberg, da Costa e Chuaqui nos apresentam, como já dissemos acima, uma matematização de uma concepção pragmática de verdade que eles denominaram de quase-verdade (cf. Mikenberg, da Costa e Chuaqui 1986). Embora náo encarem sua definição como uma exegese da posiçáo peirciana, o fato é que a definição dada por eles capta, sem dúvida alguma, aspectos relevantes e significativos da doutrina da verdade do pensador norte-americano.

Nossa finalidade agora é a de descrever, de modo sucinto e sem o simbolismo e as técnicas necessárias para sua formulaçáo precisa, a definição de da Costa e Chuaqui. Porém, antes disso, seria interessante fazer um resumo geral do trabalho desses autores, que foi muito bem sumariado por J. Corcoran.

"Filosofias Pragmáticas enfatizam a prioridade da experiência e da ação sobre o ser e o pensamento. Oponentes do pragmatismo sáo algumas vezes chamados de 'intelectualistas'. Característica das Filosofias Pragmáticas é o fato delas manterem pontos de vista claros sobre três questóes: (1) significado, (2) verdade e (3) conhecimento. Devido a extensas variaçóes entre tais filosofias, é simplista considerar qualquer combinação destes pontos de vista como típica (veja A. O. Lovejoy, J. Philos. 5 (1908), no 1, 5-12; ibid. 5 (1908), no 2, 29-39). Todavia, a seguinte combinação pode ser tida como um exemplo. (1) $\mathrm{O}$ significado de uma proposição é identificado com seu significado experimental e prático, i.e., com a totalidade das experiências possíveis que ela prediz. (2) A verdade de uma proposição consiste na realizaçáo no decurso do tempo (passado, presente e futuro) de seu sentido. (3) A crença na verdade de uma proposição é garantida pelo grau com que ela tem sido 


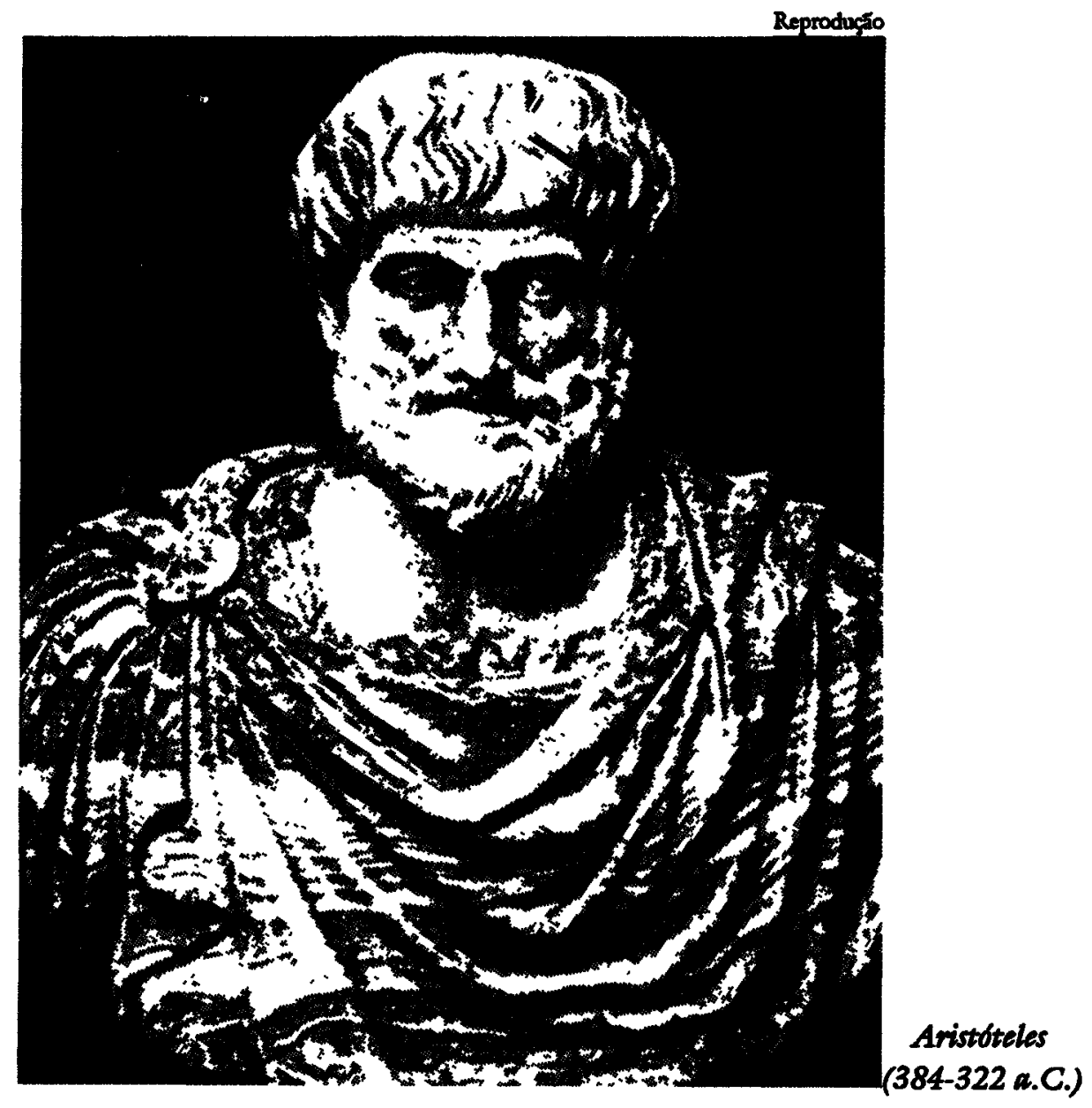

testada na prática e se mostrado satisfatória (pela pessoa ou comunidade que possui a crença)."

$A$ Teoria Pragmática da Natureza da Verdade (ponto de vista (2)) está intimamente relacionada com a Teoria Pragmática do Critério de Verdade (ponto de vista (3)), ainda que sempre é importante distinguir entre a Teoria da (a natureza da) Verdade e uma Teoria do Critério de Verdade. Esta distinção é familiar a matemáticos através dos trabalhos de Tarski, que enfatizou a correspondência como a natureza da verdade matemática e da provabilidade como o critério da verdade matemática. A demonstração de Tarski do teorema de Gödel explora esta distinção, notando que indefinibilidade aritmética da verdade aritmética (teorema da provabilidade aritmética), para implicar que verdade aritmética não é coextensiva com a provabilidade aritmética (A. Tarski, Logic, semantics, metamathematics, traduçáo inglesa, veja pp. 197-8, 246-54, Clarendon Press, Oxford, 1956; MR 17, 1171; segunda ediçăo, Hackett, Indianapolis, Ind., 1983; MR 85e: 01065; Sci. Amer. 220, 1969, 63-77, especialmente pp. 69-77). 


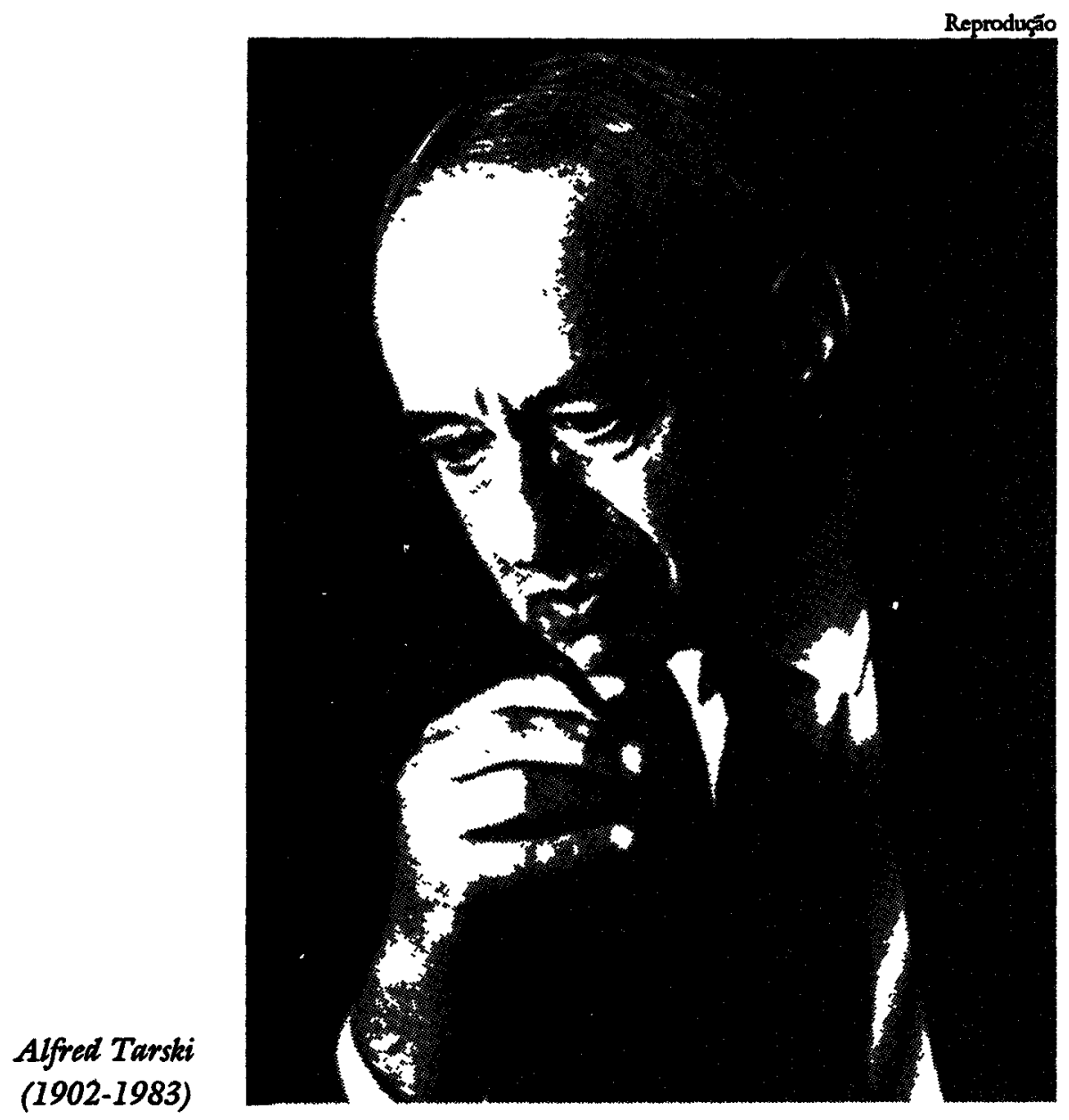

O artigo (Mikenberg, I., N. C. A. da Costa \& R. Chuaqui, Pragmatic truth and approximation to truth, "The Journal of Symbolic Logic" 51, 1986, pp. 201-221) propóe modificar a noçáo tarskiana, model-theoretic, de "uma sentença sé verdadeira em uma interpretaçáo in de modo que a noção resultante, matematicamente precisa, é fiel a uma das noçóes pragmáticas da verdade. De acordo com o artigo, o contexto completo para o uso apropriado das frases "pragmaticamente verdadeiro" $\mathrm{e}$ "pragmaticamente falso" vai além do contexto acima do uso apropriado, clássico, de "verdadeiro" e "falso" sob dois aspectos: (a) a interpretação $i$ é parcial (não necessariamente total) e (b) existe relativização a um conjunto $P$ de sentenças "estabelecidas". Em conseqüêencia, a noçáo a ser definida é expressa por "uma sentença $s$ é pragmaticamente verdadeira em uma interpretação parcial $i$ relativa a um conjunto $P$ de sentenças". A condiçáo necessária e suficiente proposta como definitiva é is $s$ as sentenças em $\mathrm{P}$ são simultaneamente satisfeitas por uma extensáo total de $i$ ". Grosso modo, de acordo com o artigo (p. 204), se uma sentença é pragmaticamente verdadeira, "ela salva as aparências". 
Os autores constroem um sistema formal de dedução à la Gentzen para acompanhar as semânticas acima. Eles obtêm um teorema de completude e alguns outros resultados matemáticos, incluindo uma demonstraçáo de um teorema sobre extensóes de grupos semi-ordenados, que originalmente foi enunciado, sem demonstração, por Tarski em 1948. Há, também, aplicaçóes ao problema em Filosofia da Ciência de explicar a idéia de uma teoria anterior ser uma "aproximação" de uma posterior, mais adequada.

O artigo não reivindica qualquer tentativa de erudiçáo suficiente para mostrar que sua definição é fiel a uma idéia endossada por um filósofo pragmático. Seu objetivo definido é mostrar que idéias matematicamente rigorosas, refletindo o pensamento pragmático, possuem conseqüências matematicamente interessantes e construir uma extensão pragmática da Teoria Clássica de Modelos (J. Corcoran, MR 88c: 03006)".

Mikenberg, da Costa e Chuaqui, seguindo Tarski, sublinham que a definiçáo de verdade pragmática ou de quase-verdade, como eles a conceberam, só pode ser feita com relaçáo a uma determinada linguagem, interpretada em uma estrutura conveniente. Uma das grandes novidades dessa concepçáo reside no fato de que as estruturas nas quais a linguagem é interpretada não sáo estruturas totais, como no caso da teoria de Tarski, mas sim estruturas parciais.

Na Teoria Clássica de Verdade de Tarski, as linguagens sáo interpretadas em estruturas que, grosso modo, se compõem de um conjunto $A$, denominado universo da estrutura e de certo conjunto $R$ de relaçóes, envolvendo objetos de A. Essas relaçóes sáo sempre definidas para todos os objetos de A: por exemplo, se tivermos uma relaçáo binária, em $\mathbf{R}$, entáo, dados dois objetos x e y quaisquer de $\mathrm{A}$, eles estão ou não ligados por essa relação. $\mathrm{Na}$ teoria de da Costa e Chuaqui isso náo ocorre, pelas razóes que passamos a expor: os objetos $\mathrm{x}$ e y de $\mathrm{A}$ podem estar ligados por uma relação de $\mathrm{R}$, podem não estar ligados pela relação ou, finalmente, podem não estar definidos se eles não possuem a relação entre si.

A partir de estruturas parciais, como acabamos de descrever, e de conjuntos de sentenças básicas que expressam proposiçóes de nossa experiência, verdadeiras ou falsas, de acordo com a Teoria da Correspondência, e de sentenças mais complexas, expressando proposiçóes aceitas previamente, define-se o conceito de verdade pragmática de uma sentença por um processo parecido com o tarskiano e que se apóia no mesmo. O resultado, entáo, é o seguinte: uma sentença sé quase-verdadeira 
ou pragmaticamente verdadeira numa determinada regiáo do conhecimento (ou numa estrutura) se tudo se passa nessa região (ou estrutura), como se $s$ fosse verdadeira de acordo com a Teoria da Correspondência. Equivalentemente, uma sentença é quase-verdadeira num domínio se, e somente se, salvar as aparências desse domínio, ou seja, funciona.

A definição de quase-verdade generaliza a definição de Tarski e seus autores constroem uma teoria generalizada de modelos que encontrou várias aplicaçōes em Lógica e em Matemática (cf. da Costa e Chuaqui (no prelo) e Mikenberg, da Costa e Chuaqui 1986).

O leitor facilmente percebe que a definição de quase-verdade satisfaz os principais requisitos a que uma definiçáo de verdade pragmática parece condicionada. Especialmente notável é o fato de que a verdade pragmática é um processo de se salvar as aparências, quando não se conhece a verdade segundo a Teoria da Correspondência. Todavia, outras interpretaçóes da Teoria da Quase-Verdade são possíveis, embora năo tenhamos tempo para abordá-las aqui.

\section{Algumas aplicações da quase-verdade}

A quase-verdade, sobretudo em decorrência dos trabalhos de Mikenberg, da Costa e Chuaqui e French, encontrou variadas aplicaçóes na Teoria da Ciência.

Chuaqui, da Costa e Mikenberg mostraram como a quase-verdade pode ser usada para se definir o conceito de aproximaçáo à verdade de teorias científicas, verdade sendo usada aqui no sentido da Teoria da Correspondência. As noçōes formuladas têm um significado matemático intrínseco e podem ser aplicados, por exemplo, em Álgebra (Mikenberg, da Costa e Chuaqui 1986), etc.

Outras aplicaçóes, devidas a S. French e N. C. A. da Costa, são as seguintes: a edificaçáo de uma nova Lógica Indutiva (consultar da Costa em Erkenntnis e da Costa e French (no prelo)) à estruturação de uma nova Teoria Subjetiva de Probabilidade do realismo e do empiricismo (cf. French (no prelo)), etc.

Constata-se, portanto, que o conceito de quase-verdade não se mostra apenas importante por formalizar e precisar uma Teoria da Verdade como a pragmática, mas encontra numerosas aplicaçóes nos mais variados domínios. Isto é sinal, segundo pensamos, de que a Teoria da Quase-Verdade se converterá numa das mais importantes teorias da Lógica atual (o surpreendente é que a quase-verdade acha-se correlacio- 
nada com a Lógica Paraconsistente (ver, por exemplo, da Costa 1989 e da Costa e Chuaqui (no prelo)).

\section{Bibliografia}

Esta bibliografia contém não apenas os artigos citados no texto, como também todos os artigos publicados ou em vias de publicaçáo sobre o tema que conseguimos arrolar.

DA COSTA, N. C. A. 1989. Logic and pragmatic truth. In: —_ Logic, Methodology and Pbilosophy of Science VIII. Edited by J. E. Fenstand et al., Elsevier Science Publishers B. V.

25, pp. 141-142.

DA COSTA, N. C. A. \& R. CHUAQUI. The logic of pragmatic truth, a aparecer.

DA COSTA, N. C. A. \& S. FRENCH, Pragmatic truth and the logic of induction, a aparecer. em Pbilosophy of Scicnce.

The model-theoretic approach in philosophy of science, a aparecer

FRENCH, S. A note on constructive empiricism and pragnentic truth, a aparecer.

GRAYLING, A. C. 1986. An Introduction to Philosophical Logic. The Harverster Press.

HAACK, S. Deviant Logic. Cambridge University Press, Cambridge, 1974.

. Philosophy of Logics. Cambridge University Press, Cambridge, 1980.

MENDELSON, E. 1979. Introduction to Mathematical Logic. D. Van Nostrand Company, New York

MIKENBERG, I., N. C. A. DA COSTA \& R. CHUAQUI. 1986. Pragmatic truth and approximation to truth. The Journal of Symbolic Logic. 51, pp. 201-221.

PEIRCE, C. S. 1965. Philosophycal Writings of Pcirce. Selected and edited by J. Buchler, Dover.

SHOENFIELD, J. P. 1967. Mathematical Logic. Addison-Wesley Publishing Company.

TARSKI, A. 1956. Der Wahrheitsbegriff in den formalisierten Sprachen, Studia Philosophica, 1, 1935, pp. 261-405. Traduzido para o inglês em Logic, Semantics, Metamathematics. Oxford University Press.

1944. The semantic conception of truth. Philosophy and Phenomenological Research. 4, pp. 341-376.

\section{Resumo}

Como se sabe existem, pelo menos, quatro teorias de verdade que se evidenciam de relevância para o filósofo que se ocupa da Teoria da Ciéncia: 1) a Teoria da Correspondência, particularmente, na forma que the confiriu A. Tarski; 2) a Teoria da Coerência; 3) a Teoria Pragmática; e 4) a Teoria da Eliminaçäo da Verdade (ou definibilidade da verdade).

Neste artigo, de caráter expositivo, se apresenta um apanhado geral de alguns desenvolvimentos técnicos que têm sido feitos nos útlimos anos sobre a verdade pragmática, que também é chamada de quase verdade.

\section{Abstract}

There are at least four theories of truth that are relevant for philosophers of science theory: 
1) Theory of Correspondence, particulary, in the way it was proposed by A. Tarsk; 2) Theory of Coherence; 3) Pragmatic Theory; and 4) Theory of the Truth Elimination (or definibility of truth).

In this expositor article, it is presented a general aspect of some technical developments that have been done recently about the Pragmatic Truth, which is also called "Quasi-Truth" .

Jair Minoro Abe é bacharel e mestre em Matemática Pura pelo Instituto de Matemática e Estatística da USP e doutorando em Lógica pela Faculdade de Filosofia, Letras e Ciências Humanas da USP. Foi professor-visitante da Universidade de Shizuoka, no Japão, e atualmente é professor do IGCE-Unesp. É, também, membro e coordenador do Grupo de Lógica e Teoria da Ciéncia do IEA/USP. 